\title{
A PROSPECTIVE STUDY OF CLINICAL PROFILE OF CHRONIC RHINOSINUSITIS IN A TERTIARY CARE CENTRE
}

\author{
Sindhu V. Nath1, Susan James' ${ }^{2}$ Nimisha Suresh ${ }^{3}$
}

${ }^{1}$ Assistant Professor, Department of ENT, Government Medical College, Thiruvananthapuram, Kerala. ${ }^{2}$ Assistant Professor, Department of ENT, Government Medical College, Thiruvananthapuram, Kerala. ${ }^{3}$ Postgraduate Student, Department of ENT, Government Medical College, Thiruvananthapuram, Kerala.

\begin{abstract}
BACKGROUND

Chronic Rhinosinusitis (CRS) is a prevalent medical disorder encountered in Otorhinolaryngology practice that has both personal and economic impact. It leads to significant patient morbidity in terms of quality of life and decreased overall productivity. Therefore, it becomes very important to understand the clinical profile of CRS patients so that proper treatment model can be advised. In this study, attempt has been made to identify the clinical profile of patients with CRS who attended Department of Otorhinolaryngology, Medical College Hospital, Thiruvananthapuram, during a period of 1 year from April 2014 - April 2015.

The aim of this study is to study the clinical profile of patients with chronic rhinosinusitis and to study the clinical profile of patients with chronic rhinosinusitis and to decide on treatment; to find out the prevalence of fungal sinusitis among chronic rhinosinusitis in population and identify the commonest strain of fungus.
\end{abstract}

\section{MATERIALS AND METHODS}

314 patients with symptoms of Chronic Rhinosinusitis were included over a period of 1 year. Demographic data, Symptomatology and Clinical signs were recorded; 3 months treatment given and later the endoscopic features and CT scan observed. Patients with persistent disease were operated upon with FESS, operative notes recorded. Per-operative polyps, fungal, mucin were subjected to HPE and fungal culture.

\section{RESULTS}

Out of 314 patients, 164 were females (52\%) and 150 were males (48\%). The commonest age group was 21 - 50 years. The commonest symptoms were Nasal block 57\%, Nasal discharge 58\% and Facial congestion 59\%; 80\% of the patients needed FESS. Operative findings included $46 \%$ had oedematous mucosa, $33.4 \%$ had polyp and $1.6 \%$ patients had fungal debris alone. Aspergillus Sp was the commonest fungus.

\section{CONCLUSION}

The mean age of Chronic Rhinosinusitis was 40 years having equal distribution among males and females. Common presenting symptoms were headache, nasal discharge and nasal obstruction. Anatomical variations like deviated nasal septum can predispose to chronic rhinosinusitis. Surgery plays a significant role in the management of refractory cases of chronic rhinosinusitis.

\section{KEYWORDS}

Sinusitis, FESS, Fungal, Oedematous, Polyp, Mucosal Oedema.

HOW TO CITE THIS ARTICLE: Nath SV, James S, Suresh N. A prospective study of clinical profile of chronic rhinosinusitis in a tertiary care centre. J. Evolution Med. Dent. Sci. 2017;6(16):1268-1275, DOI: 10.14260/Jemds/2017/276

\section{BACKGROUND \\ Definition and Classifications}

The term rhinosinusitis refers to a group of disorders characterised by inflammation of mucosa of the nose and paranasal sinuses. As the nose is invariably involved with paranasal sinuses and the mucosa of nose and paranasal sinuses lays in continuity the term rhinosinusitis is a more preferred term. ${ }^{1}$ This disease has got diverse symptomatology and has got a negative impact on quality of life. To tackle the difficult issues related to defining, staging and research of

Financial or Other, Competing Interest: None.

Submission 16-01-2017, Peer Review 08-02-2017,

Acceptance 15-02-2017, Published 23-02-2017.

Corresponding Author:

Dr. Sindhu V. Nath,

Assistant Professor,

Department of ENT,

Government Medical College,

Thiruvananthapuram,

Kerala.

E-mail: sindhuvn@gmail.com

DOI: $10.14260 /$ jemds $/ 2017 / 276$

(c) (i) $($ ) rhinosinusitis, the American Academy of Otolaryngology Head and Neck Surgery convened a multidisciplinary in August 1996.(2) As a result of it the article "Adult Rhinosinusitis Defined" has emerged in 1997 and was endorsed by the American Academy of Otolaryngologic Allergy and American Rhinologic Society (AAO-HNS) and later was modified by contributions of Lanza and Kennedy.(3) Acute rhinosinusitis is typically subdivided into Acute Bacterial Rhinosinusitis (ABRS) or Acute Viral Rhinosinusitis (AVRS).(4) Acute viral rhinosinusitis is usually self-limited, whereas bacterial rhinosinusitis presents with most of the symptoms they became the point of interest. ${ }^{5}$ Rhinosinusitis can present in any age group without any gender predisposition. A study conducted by Wayne D Hsueh et $\mathrm{al}^{6}$ on identifying clinical symptoms on improving the symptomatic diagnosis of CRS showed no significant differences between CRS and non-CRS patients in terms of age, sex and race. There is lack of evidence whether the male and female patients with rhinosinusitis were different and whether they should be treated differently. So a focused research in this area is warranted.(7) It affects between 5 to $15 \%$ of population according to Western literature.(8) 


\section{Fungal Hypothesis 9}

The fungal hypothesis proposes that patients with CRS mount an eosinophilic response to fungi with initial evidence showing some degree of fungi and eosinophilic mucin in all patients with CRS. The intranasal fungi in a patient with CRS would probably exacerbate the disease process through protease effects on nasal epithelial cells as well as activated eosinophils and lymphocytes present in the nose.

\section{MATERIALS AND METHODS}

This is a Prospective study conducted between April 2014 and March 2015 in the ENT OPD of Government Medical College, Thiruvananthapuram; 314 patients with chronic rhinosinusitis attending the Outpatient Department of ENT, Government Medical College, Thiruvananthapuram were included. All patients attending the Outpatient Department were studied.

\section{Inclusion Criteria}

1. Chronic rhinosinusitis patients fulfilling the diagnostic criteria.

2. Patients in the age group of $18-70$ years.

3. Both males and females.

\section{Exclusion Criteria}

1. Patients less than 18 years and more than 70 years.

2. Those not willing to participate in the study.

3. Patients who underwent previous nasal surgery.

\section{Data Collection}

Semi-structured questionnaire regarding detailed history, duration and severity of symptoms are collected from the patients who attended the Outpatient Department of Otorhinolaryngology. Patients were examined in detail which included anterior rhinoscopy and diagnostic nasal endoscopy. Patients were given medical management with antibiotics, topical steroids, decongestants and nasal douche for 3 weeks and kept under followup. Patients were continued on topical steroids for 3 months, following which patients were reexamined. Computed tomography of nose and paranasal sinuses (Axial, coronal and sagittal view) was taken for patients without symptomatic improvement. They were taken up for Functional Endoscopic Sinus Surgery. Per-operative findings were recorded. Allergic mucin noted during surgery was sent for microbiology, fungal culture and sensitivity and fungal strain identified and recorded. A semi-structured questionnaire was used to elicit demographic data, anterior rhinoscopy and diagnostic nasal endoscopy. Wherever necessary computed tomography of nose and paranasal sinuses was done. Functional Endoscopic Sinus Surgery was done in patients with correct indications. Swabs and materials from the surgical site were sent to Microbiology Department for fungal strain identification and culture.

\section{Data Analysis}

Qualitative data is expressed in percentage and proportion. Quantitative data is expressed in mean and standard deviation. Association is measured by Chi square test. Data entered in Microsoft Excel and analysed using SPSS.

\section{OBSERVATIONS AND RESULTS}

Among the total number of 314 patients' data collected 164 were females (52\%) and 150 were males (48\%) (Table 1).

\begin{tabular}{|c|c|c|}
\hline Sex & No. of Patients & Percentage \\
\hline Female & 164 & $52 \%$ \\
\hline Male & 150 & $48 \%$ \\
\hline Total & $\mathbf{3 1 4}$ & \\
\hline \multicolumn{2}{|c|}{ Table 1. Percentage Distribution of Sample according to } \\
Sex
\end{tabular}

Among 314 patients in the study, the most common age group was $31-40$ years (23\%). Others were $41-50$ years (22\%), 21-30 years (19\%), 51 - 60 years $(17 \%), 10-20$ years (11\%) and 61-70 years (8\%). Mean age group of sample was found to be 40 years with standard deviation of 14.2 (Table 2).

\begin{tabular}{|c|c|c|c|c|}
\hline Age in Years & Male & Female & $\begin{array}{c}\text { Total No. } \\
\text { of Patients }\end{array}$ & $\%$ \\
\hline $10-20$ Years & 21 & 12 & 33 & $11 \%$ \\
\hline 21 - 30 Years & 27 & 33 & 60 & $19 \%$ \\
\hline $31-40$ Years & 29 & 44 & 73 & $23 \%$ \\
\hline $41-50$ years & 35 & 35 & 70 & $22 \%$ \\
\hline $51-60$ Years & 24 & 29 & 53 & $17 \%$ \\
\hline $61-70$ Years & 14 & 11 & 25 & $8 \%$ \\
\hline \multicolumn{3}{|c|}{ Mean \pm SD } & $39.9 \pm 14.2$ & \\
\hline
\end{tabular}

Among the 314 patients observed, the average period for which the patients suffered from chronic rhinosinusitis was 3.7 years. Duration varied from 4 months to 40 years (Table 3).

\begin{tabular}{|c|c|c|}
\hline $\begin{array}{c}\text { Duration of Symptoms } \\
\text { in Years }\end{array}$ & $\begin{array}{c}\text { No. of } \\
\text { Patients }\end{array}$ & Percentage \\
\hline $1-5$ Years & 249 & $79.3 \%$ \\
\hline $6-10$ Years & 49 & $15.6 \%$ \\
\hline $11-15$ Years & 8 & $2.5 \%$ \\
\hline $16-20$ Years & 5 & $1.6 \%$ \\
\hline $21-25$ Years & 0 & $0.0 \%$ \\
\hline $26-30$ Years & 1 & $0.3 \%$ \\
\hline $31-35$ Years & 0 & $0.0 \%$ \\
\hline $36-40$ Years & 2 & $0.6 \%$ \\
\hline Total & 314 & \\
\hline Table 3. Duration of Symptoms \\
\hline
\end{tabular}

Among the 314 patients, majority of patients (79\%) had symptoms for 1 - 5 years. Among the 314 patients, it was found that the most common symptom was headache $(84 \%)$ followed by nasal discharge (59\%), nasal block (58\%) and facial congestion (57\%). Other results and analysis symptoms were facial pain, halitosis, anosmia/hyposmia, fatigue, fever, epistaxis, cough and dental pain (Table 4).

\begin{tabular}{|c|c|c|}
\hline Presenting Symptoms & Present & Percentage (\%) \\
\hline Nasal Block & 183 & $58 \%$ \\
\hline Facial Pain & 141 & $45 \%$ \\
\hline Facial Congestion & 179 & $57 \%$ \\
\hline Headache & 265 & $84 \%$ \\
\hline Dental Pain & 17 & $5 \%$ \\
\hline Nasal Discharge & 186 & $59 \%$ \\
\hline Epistaxis & 45 & $14 \%$ \\
\hline Anosmia/Hyposmia & 91 & $29 \%$ \\
\hline Halitosis & 133 & $42 \%$ \\
\hline Fever & 52 & $17 \%$ \\
\hline Fatigue & 66 & $21 \%$ \\
\hline Cough & 36 & $11 \%$ \\
\hline Table 4. Presenting Symptoms \\
\hline
\end{tabular}




\begin{tabular}{|c|c|c|}
\hline Category & No. of Patients & Percentage \\
\hline No block & 131 & $42 \%$ \\
\hline Unilateral & 50 & $16 \%$ \\
\hline Bilateral & 133 & $42 \%$ \\
\hline Total & $\mathbf{3 1 4}$ & $100 \%$ \\
\hline \multicolumn{3}{|c|}{ Table 5. Nasal Block }
\end{tabular}

Among 314 patients 58\% had nasal block, of which $42 \%$ had bilateral nasal block and $16 \%$ had unilateral nasal block (Table 5).

\begin{tabular}{|c|c|c|}
\hline Nature & No. of Patients & Percentage \\
\hline No block & 131 & $42 \%$ \\
\hline Non-Progressive & 29 & $9 \%$ \\
\hline Progressive & 154 & $49 \%$ \\
\hline Total & $\mathbf{3 1 4}$ & \\
\hline \multicolumn{2}{|c|}{ Table 6. Nasal Block Nature } \\
\hline
\end{tabular}

Among 314 patients $42 \%$ did not have nasal block, $49 \%$ had progressive nasal block and $9 \%$ had non-progressive nasal block (Table 6).

\begin{tabular}{|c|c|c|}
\hline Nature & No. of Patients & Percentage \\
\hline Non-Progressive & 29 & $16 \%$ \\
\hline Progressive & 154 & $84 \%$ \\
\hline Total & $\mathbf{1 8 3}$ & $\mathbf{1 0 0 \%}$ \\
\hline \multicolumn{2}{|r|}{ Table 7. Nasal Block Nature } \\
\hline
\end{tabular}

Among the patients with nasal block (183 patients), 84\% patients had progressive nasal block and $16 \%$ patients had non-progressive nasal block (Table 7).

\begin{tabular}{|c|c|c|}
\hline Nasal Block Severity & No. of Patients & Percentage \\
\hline No Nasal Block & 132 & $42 \%$ \\
\hline Mild Nasal Block & 15 & $5 \%$ \\
\hline Moderate Nasal Block & 128 & $41 \%$ \\
\hline Severe Nasal Block & 39 & $12 \%$ \\
\hline Total & 314 & $100 \%$ \\
\hline
\end{tabular}

Among 314 patients in the study $42 \%$ patients did not have nasal block, 5\% had mild nasal block, $41 \%$ had moderate nasal block and $12 \%$ had severe nasal block (Table 8).

\begin{tabular}{|c|c|c|}
\hline Facial Pain & No. of Patients & Percentage \\
\hline No Facial Pain & 173 & $55 \%$ \\
\hline Facial Pain & 141 & $45 \%$ \\
\hline Total & $\mathbf{3 1 4}$ & $100 \%$ \\
\hline \multicolumn{3}{|c|}{ Table 9. Facial Pain } \\
\hline
\end{tabular}

Among 314 patients, $45 \%$ patients had facial pain and 55\% did not have facial pain (Table 9).

\begin{tabular}{|c|c|c|}
\hline Facial Pain & No. of Patients & Percentage \\
\hline No Facial Pain & 173 & $55 \%$ \\
\hline Mild Facial Pain & 25 & $8 \%$ \\
\hline Moderate Facial Pain & 111 & $35 \%$ \\
\hline Severe Facial Pain & 5 & $2 \%$ \\
\hline Total & 314 & $100 \%$ \\
\hline
\end{tabular}

Among 314 patients in the sample 55\% patients did not have facial pain, $8 \%$ patients had mild facial pain, $35 \%$ had moderate facial pain and $2 \%$ of patients had severe facial pain (Table 10).

\begin{tabular}{|c|c|c|}
\hline Facial Congestion & No. of Patients & Percentage \\
\hline No Facial Congestion & 135 & $43 \%$ \\
\hline Facial Congestion & 179 & $57 \%$ \\
\hline Total & $\mathbf{3 1 4}$ & \\
\hline \multicolumn{2}{|c|}{ Table 11. Facial Congestion } \\
\hline
\end{tabular}

Among 314 patients, 57\% patients had facial congestion and $43 \%$ of patients did not have facial congestion (Table 11).

\begin{tabular}{|c|c|c|}
\hline Facial Congestion & No. of Patients & Percentage \\
\hline No Facial Congestion & 135 & $43 \%$ \\
\hline Mild Facial Congestion & 31 & $10 \%$ \\
\hline Moderate Facial Congestion & 137 & $44 \%$ \\
\hline Severe Facial Congestion & 11 & $3 \%$ \\
\hline Total & 314 & \\
\hline \multicolumn{3}{|c|}{ Table 12. Facial Congestion Severity } \\
\hline
\end{tabular}

Among 314 patients in the study, $10 \%$ of patients had mild facial congestion, $44 \%$ had moderate facial congestion, $3 \%$ of patients had severe facial congestion and $43 \%$ patients did not have facial congestion (Table 12).

\begin{tabular}{|c|c|c|}
\hline Nasal Discharge & No. of Patients & Percentage \\
\hline Present & 186 & $59 \%$ \\
\hline Absent & 128 & $41 \%$ \\
\hline Total & $\mathbf{3 1 4}$ & $\mathbf{1 0 0} \%$ \\
\hline \multicolumn{2}{|c|}{ Table 13. Nasal Discharge } \\
\hline
\end{tabular}

Among 314 patients in the study, $59 \%$ of patients had nasal discharge as one of the presenting symptom and $41 \%$ did not have nasal discharge (Table 13).

\begin{tabular}{|c|c|c|}
\hline Hyposmia & Anosmia & $\begin{array}{c}\text { Absence of Olfactory } \\
\text { Disturbance }\end{array}$ \\
\hline 78 & 13 & 223 \\
\hline $25 \%$ & $4 \%$ & $71 \%$ \\
\hline \multicolumn{2}{|c|}{ Table 14. Olfactory Disturbance } \\
\hline
\end{tabular}

While analysing 314 patients in the study, $71 \%$ of patients did not have any olfactory disturbance and $29 \%$ of patients were having olfactory disturbance, of which $4 \%$ of patients were having Anosmia and $25 \%$ of patients were having Hyposmia (Table 14).

\begin{tabular}{|c|c|c|}
\hline Headache & No. of Patients & Percentage \\
\hline No Headache & 49 & $16 \%$ \\
\hline Mild Headache & 11 & $3 \%$ \\
\hline Moderate Headache & 71 & $23 \%$ \\
\hline Severe Headache & 183 & $58 \%$ \\
\hline Total & $\mathbf{3 1 4}$ & $\mathbf{1 0 0 \%}$ \\
\hline \multicolumn{2}{|c|}{ Table 15. Headache } \\
\hline
\end{tabular}

Among 314 patients in the study, $16 \%$ did not have headache, $3 \%$ had mild headache and $23 \%$ had moderate headache and severe headache in $58 \%$ of patients (Table 15).

\begin{tabular}{|c|c|c|}
\hline Halitosis & No. of Patients & Percentage \\
\hline Present & 133 & $42 \%$ \\
\hline Absent & 181 & $58 \%$ \\
\hline Total & $\mathbf{3 1 4}$ & \\
\hline \multicolumn{3}{|c|}{ Table 16. Halitosis } \\
\hline
\end{tabular}


Among 314 patients in the study, $42 \%$ of patients had halitosis and $58 \%$ of patients did not have Halitosis (Table 16).

\begin{tabular}{|c|c|c|}
\hline Dental Pain & No. of Patients & Percentage \\
\hline No Dental Pain & 303 & $96 \%$ \\
\hline Mild Dental Pain & 5 & $2 \%$ \\
\hline Moderate Dental Pain & 6 & $2 \%$ \\
\hline Severe Dental Pain & 0 & $0 \%$ \\
\hline \multicolumn{2}{|c|}{ Total Table 17. Dental Pain } \\
\hline
\end{tabular}

Among 314 patients in the study, 96\% patients did not have dental pain, $2 \%$ had mild dental pain and $2 \%$ had moderate dental pain (Table 17).

\begin{tabular}{|c|c|c|}
\hline Cough & No. of Patients & Percentage \\
\hline Present & 36 & $11 \%$ \\
\hline Absent & 278 & $89 \%$ \\
\hline Total & $\mathbf{3 1 4}$ & $\mathbf{1 0 0 \%}$ \\
\hline \multicolumn{3}{|c|}{ Table 18. Cough } \\
\hline
\end{tabular}

Among 314 patients in the study, $11 \%$ of patients had cough and $89 \%$ of patients did not have Cough (Table 18).

\begin{tabular}{|c|c|c|}
\hline Fatigue & No. of Patients & Percentage \\
\hline Present & 66 & $21 \%$ \\
\hline Absent & 248 & $79 \%$ \\
\hline Total & $\mathbf{3 1 4}$ \\
\hline \multicolumn{3}{|c|}{ Table 19. Fatigue } \\
\hline
\end{tabular}

Among 314 patients, $21 \%$ of patients had fatigue and $79 \%$ of patients did not have fatigue (Table 19).

\begin{tabular}{|c|c|c|}
\hline Fever & No. of Patients & Percentage \\
\hline Present & 66 & $21 \%$ \\
\hline Absent & 248 & $79 \%$ \\
\hline Total & $\mathbf{3 1 4}$ & $\mathbf{1 0 0} \%$ \\
\hline \multicolumn{3}{|c|}{ Table 20. Fever } \\
\hline
\end{tabular}

Among 314 patients, $21 \%$ of patients had fever and $79 \%$ of patients did not have fever (Table 20).

\begin{tabular}{|c|c|c|}
\hline Epistaxis & No. of Patients & Percentage \\
\hline Present & 45 & $14 \%$ \\
\hline Absent & 269 & $86 \%$ \\
\hline Total & $\mathbf{3 1 4}$ & $\mathbf{1 0 0} \%$ \\
\hline \multicolumn{3}{|c|}{ Table 21. Epistaxis } \\
\hline
\end{tabular}

While analysing 314 patients, it was found that $14 \%$ of patients had Epistaxis as one of the presenting symptom and 86\% did not have Epistaxis (Table 21).

\begin{tabular}{|c|c|c|}
\hline Asthma & No. of Patients & Percentage \\
\hline Present & 16 & $5 \%$ \\
\hline Absent & 298 & $95 \%$ \\
\hline Total & $\mathbf{3 1 4}$ & $\mathbf{1 0 0 \%}$ \\
\hline \multicolumn{3}{|c|}{ Table 22. Asthma } \\
\hline
\end{tabular}

Among 314 patients in the study, $5 \%$ of patients had asthma and $95 \%$ of patients did not have Asthma (Table 22).

\begin{tabular}{|c|c|c|}
\hline Allergy & No. of Patients & Percentage \\
\hline Present & 201 & $64 \%$ \\
\hline Absent & 113 & $36 \%$ \\
\hline Total & $\mathbf{3 1 4}$ & \\
\hline \multicolumn{3}{|c|}{ Table 23. Allergy } \\
\hline
\end{tabular}

Among 314 patients, $64 \%$ of patients gave history of allergy and $36 \%$ of patients did not have allergy (Table 23).

\begin{tabular}{|c|c|c|}
\hline Septum & Patients & Percentage \\
\hline Deviated & 253 & $81 \%$ \\
\hline Not Deviated & 61 & $19 \%$ \\
\hline Total & $\mathbf{3 1 4}$ & $\mathbf{1 0 0} \%$ \\
\hline \multicolumn{2}{|c|}{ Table 24. Examination Findings of Septum } \\
\hline
\end{tabular}

Distribution of sample according to position of septum. While analysing the septum of 314 patients, it was found that $81 \%$ of patients had a deviated nasal septum and in $19 \%$ patient's septum was central (Table 24).

\begin{tabular}{|c|c|c|}
\hline Mucosal Congestion & Patients & Percentage \\
\hline Present & 262 & $83 \%$ \\
\hline Absent & 52 & $17 \%$ \\
\hline Total & $\mathbf{3 1 4}$ & $\mathbf{1 0 0} \%$ \\
\hline \multicolumn{2}{|c|}{ Table 25. Mucosal Congestion } \\
\hline
\end{tabular}

While analysing 314 patients, it was found that $83 \%$ of patients had mucosal congestion on examination and $17 \%$ of patients did not have mucosal congestion (Table 25).

\begin{tabular}{|l|c|c|}
\hline \multicolumn{3}{|c|}{ Nasal Discharge } \\
\hline 98 & 158 & 58 \\
\hline $31 \%$ & $50 \%$ & $19 \%$ \\
\hline \multicolumn{3}{|c|}{ Examination Findings of Septum } \\
\hline \multicolumn{2}{|c|}{ Table 26. Other Examination Findings of Nasal } \\
Discharge \\
\hline
\end{tabular}

While analysing 314 patients $68 \%$ of patients had nasal discharge on examination, of which $50 \%$ had mucoid discharge and $19 \%$ had purulent discharge; $31 \%$ of patients did not have any nasal discharge (Table 26).

\begin{tabular}{|c|c|c|}
\hline Absent & Unilateral & Bilateral \\
\hline 216 & 30 & 68 \\
\hline $69 \%$ & $9 \%$ & $22 \%$ \\
\hline \multicolumn{3}{|c|}{ Table 27. Polyp } \\
\hline
\end{tabular}

Distribution of sample according to polyp. While analysing 314 patients in the study $31 \%$ of patients had nasal polyp on examination, of which $9 \%$ had unilateral nasal polyp and $22 \%$ had bilateral nasal polyp; $69 \%$ of patients did not have any nasal polyp (Table 27).

\begin{tabular}{|c|c|c|}
\hline Posterior Rhinoscopy & No. of Patients & Percentage \\
\hline Normal & 146 & $47 \%$ \\
\hline Discharge & 106 & $34 \%$ \\
\hline Polyp & 42 & $13 \%$ \\
\hline Discharge and Polyp & 20 & $6 \%$ \\
\hline \multicolumn{2}{|c|}{ Table 28. Posterior Rhinoscopy } \\
\hline
\end{tabular}

Distribution of sample according to posterior rhinoscopy findings.

During posterior rhinoscopy examination of 314 patients, $47 \%$ patients were normal and $34 \%$ patients had discharge, $13 \%$ polyp and $6 \%$ with both polyp and discharge (Table 28 ). While analysing the endoscopic score of 314 patients, the average score was 5.59 which varied from $0-12$. While analysing the CT score of 254 patients, the average score was 11.04 , which varied from 2 to 22 . CT was taken only in patients 
whose symptoms persisted even after 3 months of medical treatment (Table 28).

\begin{tabular}{|c|c|c|}
\hline Management & Patients & Percentage \\
\hline Medical Management & 60 & $20 \%$ \\
\hline Medical + Surgical Management & 254 & $80 \%$ \\
\hline Total & $\mathbf{3 1 4}$ & $\mathbf{1 0 0} \%$ \\
\hline \multicolumn{2}{|c|}{ Table 29. Management } \\
\hline
\end{tabular}

Distribution of sample according to mode of treatment. Among 314 patients included in the study, 20\% of patients were managed medically and rest $80 \%$ were managed with combined medical and surgical management (Table 29).

\begin{tabular}{|c|c|c|}
\hline Findings & $\begin{array}{c}\text { No. of } \\
\text { Patients }\end{array}$ & $\%$ \\
\hline Oedematous mucosa & 116 & $46 \%$ \\
\hline Polyp & 85 & $33.4 \%$ \\
\hline Fungal debris & 4 & $1.6 \%$ \\
\hline Oedematous mucosa + Pus & 11 & $4.3 \%$ \\
\hline Oedematous mucosa + Polyp & 7 & $2.8 \%$ \\
\hline $\begin{array}{c}\text { Oedematous mucosa + Fungal } \\
\text { debris }\end{array}$ & 13 & $5.1 \%$ \\
\hline $\begin{array}{c}\text { Oedematous mucosa + Fungal } \\
\text { debris + Pus }\end{array}$ & 8 & $3.1 \%$ \\
\hline Polyp + Fungal debris & 1 & $0.3 \%$ \\
\hline $\begin{array}{c}\text { Oedematous mucosa + Polyp + } \\
\text { Fungal debris }\end{array}$ & 7 & $2.8 \%$ \\
\hline Polyp + Pus & 1 & $0.3 \%$ \\
\hline $\begin{array}{l}\text { Oedematous mucosa + Polyp + } \\
\text { Fungal }\end{array}$ & 1 & $0.3 \%$ \\
\hline Debris + Pus & & \\
\hline
\end{tabular}

Among 254 patients who underwent surgery, $46 \%$ of patients had oedematous mucosa, $33.4 \%$ of patients had polyp, $1.6 \%$ patients had fungal debris alone, $4.3 \%$ of patients had oedematous mucosa and pus, $2.8 \%$ of patients had oedematous mucosa and polyp, $5.1 \%$ of patients had oedematous mucosa and fungal debris, $3.1 \%$ of patients had oedematous mucosa, fungal debris and pus, $0.3 \%$ of patients had polyp and fungal debris, $2.8 \%$ of patients had oedematous mucosa, polyp and fungal debris, polyp and pus was present in $0.3 \%$ of patients and $0.3 \%$ of patients had oedematous mucosa, polyp, fungal debris and pus. Among 254 patients who underwent surgery, 34 patients had fungal debris $(10.8 \%$ among total CRS patients) (Table 30).

\begin{tabular}{|c|c|c|c|c|}
\hline \multicolumn{5}{|c|}{ Microbiology - Fungal Strain } \\
\hline Aspergillus & Mucor & Candida & Curvularia & Bipolaris \\
\hline 32 & 1 & 1 & 0 & 0 \\
\hline $94 \%$ & $3 \%$ & $3 \%$ & $0 \%$ & $0 \%$ \\
\hline \multicolumn{5}{|c|}{ Table 31. Fungal Strain } \\
\hline
\end{tabular}

Among 34 patient's sample sent for fungal culture and sensitivity, 94\% of fungal species isolated were Aspergillus, 3\% Mucor and 3\% Candida (Table 31).

\section{DISCUSSION}

This study included 314 consecutively selected patients with chronic rhinosinusitis, who presented to the Outpatient Department of Otorhinolaryngology, Medical College, Thiruvananthapuram during the study period of 1 year from April 2014 to April 2015. In the present study, a humble attempt was made to identify the clinical profile of patients with chronic rhinosinusitis. Patients who were taken up for surgery were followed up to operation table to find out the intraoperative findings and the patients with fungal sinusitis were noted and an attempt was also made to identify the species of fungus from microbiology. The results obtained were compared with many studies conducted previously. In the study, chronic rhinosinusitis was having an approximately equal distribution among males and females; Males $48 \%$ and Females 52\% with a ratio of 1.08:1. Quing Ling Fu et al(9) had $51.2 \%$ females in their study. Engin Dursun et al(10) had a similar ratio of 1.1:1, Tomasz Grzegorzek et al(11) had a ratio of 1:1, Seyyed Abdollan Madani et al(12) and Ayman Al Madani et al(13) had males more than females in their study. Francis T K et al(14) male-to-female ratio of 1.1:1. The mean age group of presentation was 40 years in the study with a standard deviation of 14.2, which coincides with studies of Ayman Al Madani et al(13) where most common age group was 40 years. S P Gulati et al(15) had it as $30-37$ years of age. Tomasz Grzegorzek et al(11) had a mean age group of 46.5 years, Bhattacharyya et al(16) had a mean age group of 42.3 years and James $\mathrm{N}$ Baraniuk et al(17) had a mean age group of 45.1 years. In our study, the average duration of symptoms was 3.7 years. Majority of patients had a duration of 1 - 5 years. Arild Danielsen et al(18) had mean symptom period as 2 to 12 years. In this study the common presenting symptoms were headache, nasal block and facial congestion, which coincided with studies of Bhattacharyya et al(16); $58 \%$ patients presented with nasal block in our study, among which $42 \%$ had bilateral and $16 \%$ had unilateral nasal block. Andre Alencar et al(19) had $83.7 \%$ of patients with nasal block. Bhattacharya N et al(16) had $51.8 \%$ patients with nasal block. Mohammed Naieni et al(20) had $79.31 \%$ and $\mathrm{T}$ Shivakumar et al(21) had $86.66 \%$ patients with nasal block. Y Bajaj et al(22) and S P Gulati et al(15) showed the most common symptom as nasal block. Francis $\mathrm{T}$ K et al(14) had $84 \%$ patients with nasal obstruction. In this study, $45 \%$ patients presented with facial pain which coincided with Bhattacharya $\mathrm{N}$ et al(23) with $47.3 \%$ patients with facial pain. Andre Alencar et al(19) had a variable presentation of facial pain in up to $80 \%$ of patients. D Hastan et al (24) had $64.7 \%$ patients with facial pain. T Shivakumar et al(21) had $73.3 \%$ patients with facial pain; $57 \%$ patients presented with facial congestion in our study. Bhattacharya $\mathrm{N}$ et al(23) had approximately $47 \%$ patients with facial congestion. Francis $\mathrm{T}$ $\mathrm{K}$ et al(14) had $79 \%$ patients with facial congestion. In this study, $59 \%$ of patients had history of nasal discharge which coincides with the study of $\mathrm{T}$ Shivakumar et al(21) where $58.09 \%$ patients had nasal discharge. Mohammed Naiemi et al(20) had $75.64 \%$ patients with nasal discharge. Tomasz Grzegorzek et al(11) had $67.92 \%$ patients with nasal discharge. Wilma $\mathrm{T}$ Anselmo et al(25) had $63.6 \%$ patients with nasal discharge. Olfactory disturbance was present in $29 \%$ patients in our study, of which $14 \%$ (13 patients) had anosmia and 86\% (78 patients) had hyposmia. Wilma T Anselmo et al(25) had $46 \%$ patients with olfactory disturbance. Mohammad Naiemi et al(19) had $87.18 \%$ patients with olfactory disturbance. T Shivakumar et al(21) had $77.14 \%$ patients with olfactory disturbance. In our study, $84 \%$ patients presented with headache. Tomasz Grzegorzek et al(11) had $56.6 \%$ patients with headache. $\mathrm{H}$ Gheriani et al(26) had $43.5 \%$ patients who had 
headache. T Shivakumar et al(21) had $62.83 \%$ patients with headache and Mohammed Naeimi et al(20) had $38.46 \%$ patients with headache. In this study, $42 \%$ patients presented with history of halitosis. Mohammad Naeimi et al(20) had $50 \%$ patients with halitosis. T Shivakumar et al(21) had $26.6 \%$ with halitosis, $5 \%$ patients had history of dental pain in our study. $\mathrm{T}$ Shivakumar et al(21) had $10.4 \%$ patients with dental pain and Mohammad Naiemi et al(20) had $70 \%$ of patients with dental pain. It was observed that $11 \%$ of patients had history of cough in our study, which coincides with the study of T Shivakumar et al,(21) where $11.42 \%$ patients had history of cough. Mohammad Naeimi et al(20) observed $45 \%$ patients with cough. A H Morice committee members(27) had $4 \%$ patients with cough; $21 \%$ patients had fatigue in our study. James $\mathrm{N}$ Baraniuk et al(28) had $26 \%$ patients with fatigue. T Shivakumar et al(21) had $30.47 \%$ patients with fatigue. In our study, $21 \%$ patients had history of fever (during acute exacerbations). Mohammad Naeimi et al(20) had 55\% patients with fever; $14 \%$ of patients had history of epistaxis during the course of disease in our study. Isek K R et al(29) had $22 \%$ patients with epistaxis. In this study, 5\% patients had history of asthma. Wilma $\mathrm{T}$ Anselmo et al(25) had 7\% patients with asthma. Ahammed $\mathrm{R}$ Sedaghat et al(30) observed $19 \%$ patients with history of asthma. Tomasz Grzegorzek et al(11) had $26.8 \%$ with asthma. L Badia et al(31) had $50 \%$ patients with coexistent asthma. D Jarvis et al(32) had a strong association between asthma and chronic rhinosinusitis. Jens U et al observed(33) 71\% patients with history of asthma. In our study, $64 \%$ patients gave history of allergy. Engin Dursun et al(10) observed coexistence of allergy in $36.2 \%$ of patients. Isek KR et al(29) observed $28.8 \%$ of patients with associated allergy. Ahmad R Sedaghat et al(30) observed an association of $27.5 \%$ patients with allergy; $81 \%$ patients had deviated nasal septum on examination in this study, which was similar to the study conducted by Seyyed Madani et al,(12) in which nasal septal deviation was observed in $81.7 \%$ of patients. V K Poorey and Neha Gupta(34) observed a strong correlation between nasal septal deviation and sinus disease. Similarly Calhoun et al, RPS Harar and Zachary M Sole $(35,36,37)$ also observed a strong association between sinonasal disease and deviated nasal septum. T Shivakumar et al(21) had $51.42 \%$ patients with nasal septal deviation. In this study, mucosal congestion was observed in $83 \%$ patients. In this study, nasal discharge was observed in $69 \%$ of patients, of which $50 \%$ were mucoid and 19\% were purulent which coincides with the study conducted by Tomasz Grzegorzek et al(10) in which nasal discharge was observed in $67.92 \%$ of patients. T Shivakumar et al(21) observed mucopus in $19.07 \%$ patients. In our study, nasal polyposis was observed in 31\% of patients, of which $9 \%$ were unilateral and $22 \%$ were bilateral. Also in $19 \%$ of patients, polyp was visible on posterior rhinoscopic examination. This coincided with the observation made by Tomasz Grzegorzek et al,(10) in which nasal polyp was found in $31.13 \%$ of patients. James $\mathrm{N}$ Baranuik et al(17) observed nasal polyposis in $50 \%$ of patients. Observation made by W J Videler et al(31) showed presence of nasal polyposis in $52 \%$ of patients and $44.7 \%$ of patients in the study by T Shivakumar et al.(21) Post nasal discharge was observed in $40 \%$ of patients in our study. Study conducted by $\mathrm{A} \mathrm{H}$ Morice ${ }^{(27)}$ committee members observed post-nasal discharge in $60 \%$ of patients. T Shivakumar et al(21) observed post-nasal discharge in $70.47 \%$ patients. In this study, the mean endoscopic score of the patients was 5.59. In the observation made by Kristen A Smith et al,(38) the mean endoscopic score was 6.3 in Asians. Observation made by Kristen A Smith et al(38) in a study was 6.9. In the present study, the mean CT score by Lund McKay score was 11.04. The observations made in mean CT score in study by Mikah M Likness et al(39) was 14.33, Kristen A Smith et el(38) was 13.5, Zachary M Sole et al(37) was 14.6 and W J Videler et al(31) was 13.5. Continued medical management were given for $20 \%$ patients and medical management followed by surgical management were given for $80 \%$ patients in our study, which almost coincides with the study of Enema Job Amodu et al ${ }^{(40)}$ in which continued medical management was given for $20.7 \%$ patients and combined medical and surgical management for $79.2 \%$ patients. In a study conducted by Kristen A Smith et al,(38) they came to the conclusion that continued medical therapy provides no additional benefits while Endoscopic Sinus Surgery provides significant improvement in several important clinical outcomes. In the present study, a humble attempt was also made to identify the percentage of fungal sinusitis among chronic rhinosinusitis and also to identify the species of fungi causing sinusitis. In this study, $10.8 \%$ of patients had fungal sinusitis. Engin Dursun and Hakan Korkmaz et al(10) observed 13\%, Seyyed Abdollah Madani et al(12) observed $12.1 \%$ and Ayman Al Madani et al(13) observed 16\% prevalence of fungal sinusitis in their study. Study conducted by Arunaloke Chakrabarti et al(41) observed a very high prevalence of $27.5 \%$ in the study. In the present study, $94 \%$ of fungi were Aspergillus species, 3\% candida and 3\% mucor. In a study conducted by Arunaloke Chakrabarti et al,(41) 97.6\% of fungi were Aspergillus species.

\section{CONCLUSION}

The mean age group of patients with chronic rhinosinusitis was 40 years. Chronic rhinosinusitis have almost equal distribution among males and females. Common presenting symptoms were headache, nasal discharge and nasal obstruction. Anatomical variations like deviated nasal septum can predispose to chronic rhinosinusitis. Chronic rhinosinusitis is more common in patients with allergic rhinitis. Mucosal congestion, oedematous mucosa and polyp were the common findings during examination. Most common fungal species isolated in culture was Aspergillus. Surgery plays a significant role in the management of refractory cases of chronic rhinosinusitis.

\section{Limitations}

The sample size was very small compared to the global burden of chronic rhinosinusitis. The time period of study was limited. Being a tertiary care centre, we had a refractory group of patients. So a good number of patients needed surgical management. Allergic rhinitis was diagnosed by history, confirmatory tests were not performed. Long term followup is needed to assess the surgical results.

\section{REFERENCES}

[1] Scott - Brown's Otorhinolaryngology. Head and Neck Surgery. $7^{\text {th }}$ edn. Part 13. 2008:1440-48, 1473-74, 147990. 
[2] Report of the Rhinosinusitis Task Force Committee Meeting. Alexandria, Virginia, August 17, 1996. Otolaryngology Head and Neck Surgery 1997;117(3 Pt 2):S1-68.

[3] Lanza DC, Kennedy DW. Adult rhinosinusitis defined Otolaryngology- Head and Neck Surgery 1997;117(3 Pt 2):S1-7.

[4] Cherry DK, Woodwell DA. National Ambulatory Medical Care Survey: 2000 summary, National Center for Health Statistics Vital Health. Adv Data 2002;(328):1-32.

[5] Fokkens WJ, Lund VJ, Mullol J, et al. EPOS 2012: European position paper on rhinosinusitis and nasal polyps 2012. A summary for otorhinolaryngologists. Rhinology 2012;50(1):1-12.

[6] Hsueh WD, Conley DB, Kim H, et al. Identifying the clinical symptoms for improving the symptomatic diagnosis of chronic rhinosinusitis. Int Forum Allergy Rhinol 2013;3(4):307-14.

[7] Ference EH, Tan BK, Hulse KE, et al. Commentary on gender differences in prevalence, treatment and quality of life of patients with chronic rhinosinusitis. Allergy Rhinol (Providence) 2015;6(2):82-8.

[8] Benninger MS, Ferguson BJ, Hadley JA, et al. Adult chronic rhinosinusitis definitions, diagnosis, epidemiology and pathophysiology. Otolaryngology Head and Neck Surgery 2003;129(3 Suppl)S1-32.

[9] $\mathrm{Fu} \mathrm{QL,} \mathrm{Ma} \mathrm{JX,} \mathrm{Ou} \mathrm{CQ,} \mathrm{et} \mathrm{al.} \mathrm{Influence} \mathrm{of} \mathrm{self-reported}$ chronic rhinosinusitis on health related quality of life: a population-based survey. PLoS One 2015;10(5):e0126881.

[10] Dursun E, Korkmaz H, Eryilmaz A, et al. Clinical predictors of long-term success after sinus surgery. Otolaryngology Head and Neck Surgery 2003;129(5):526-31.

[11] Grzegorzek T, Kolebacz B, Stryjewska-Makuch G, et al. The influence of selected preoperative factors on the course of endoscopic surgery in patients with chronic rhinosinusitis. Adv Clin Exp Med 2014;23(1):69-78.

[12] Madani SA, Hashimi SA, Modanluo M. The incidence of nasal septal deviation and its relation with chronic rhinosinusitis in patients undergoing functional endoscopic sinus surgery. JPMA 2015;65(6):612-4.

[13] Al-Madani A. Functional endoscopic sinus surgery realistic expectations Alexandra Bulletin 2007;4:885.

[14] Ling FTK, Kountakis SE. Important clinical symptoms in patients undergoing functional endscopic sinus surgery for chronic rhinosinusitis. Laryngoscope 2007;117(6):1090-3.

[15] Gulati SP, Wadhera R, Ahuja N, et al. Comparative evaluation of endoscopic with conventional septoplasty. Indian Journal of Otolaryngol and Head and Neck Surgery 2009;61(1):27-9.

[16] Bhattacharyya N. The economic burden and symptom manifestation of chronic rhinosinusitis. American Journal of Rhinology 2003;17(1):27-32.

[17] Baranuik JN, Maibach H. Pathophysiological classification of chronic rhinosinusitis. Respiratory Research 2005;6:149.

[18] Danielsen A, Olofsson J. Endoscopic endonasal sinus surgery. A long-term follow-up study. Acta Otolaryngology 1996;116(4):611-9.
[19] Alencar A, Fernandes A, Tamashiro E, et al. Rhinosinusitis evidence and experience. A summary. Braz J Otorhinolaryngology 2015;81(1 Suppl):S1-S49.

[20] Naeimi M, Garkaz M, Naeimi MR. Comparison of sinonasal symptoms in patients with nasal septal deviation and patients with chronic rhinosinusitis. Iranian Journal of Otorhinolaryngology 2013;25(70):116.

[21] Shivakumar T, Sambandan AP. Retrospective analysis of effectiveness of functional endoscopic sinus surgery in treatment of adult chronic rhinosinusitis refractory to medical treatment. Indian J Otolaryngology Head Neck Surg 2011;63(4):321-4.

[22] Bajaj Y, Gadepalli C, Reddy TN, et al. Functional endoscopic sinus surgery: review of 266 patients. The Internet Journal of Otolaryngology 2006;6(1):7.

[23] Bhattacharyya N. Clinical and symptom criteria for accurate diagnosis of chronic rhinosinusitis. Laryngoscope 2006;116(7 Pt 2 Suppl 110):1-22.

[24] Hastan D, Fokkens WJ, Bachert C, et al. Chronic rhinosinusitis in Europe - an underestimated disease. A GA²LEN study. Allergy 2011;66(9):1216-23.

[25] Anselmo-Lima WT, Sakano E. Rhinosinusitis: evidence and experience. Brazilian Journal of Otorhinolaryngology 2015;81(1):808-14.

[26] Gheriani H, Curran A, Timon C. Endoscopic sinus surgery outcome in patients with symptomatic chronic rhinosinusitis and minimal changes on computerised tomography. Ir Med J 2006;99(1):15-6.

[27] Morice AH, Fontana GA, Sovijarvi AR, et al. The diagnosis and management of chronic cough. European Resp Journal 2004;24(3):481-92.

[28] Baranuik JN, Maibach H. Pathophysiological classification of chronic rhinosinusitis. Respiratory Research 2005;6:149.

[29] Iseh KR, Makusidi M. Rhinosinusitis: a retrospective analysis of clinical pattern and outcome in North western Nigeria. Ann Afr Med 2010;9(1):20-6.

[30] Sedaghat AR, Gray ST, Caradonna SD, et al. Clustering of chronic rhinosinusitis symptomatology reveals novel associations with objective clinical and demographic characteristics. Am J Rhinol Allergy 2015;29(2):100-5.

[31] Videler WJ, Badia L, Harvey RJ, et al. Lack of efficacy of long-term, low-dose azithromycin in chronic rhinosinusitis: a randomized control trial. Allergy 2011;66(11):1457-68.

[32] Jarvis D, Newson R, Lotvall J, et al. Asthma in adults and its association with chronic rhinosinusitis. The GA2 2 EN survey in Europe. Allergy 2012;67(1):91-8.

[33] Ponikau JU, Sherris DA, Kita H, et al. Intranasal antifungal treatment in 51 patients with chronic rhinosinusitis. J Allergy Clin Immunol 2002;110(6):862-6.

[34] Poorey VK, Gupta N. Endoscopic and Computed Tomographic influence of nasal septal deviation on lateral wall of nose and its relation to sinus diseases. Indian J Otolaryngol Head Neck Surg 2014;66(3):330-5.

[35] Calhoun KH, Waggenspack GA, Simpson CB, et al. Computed tomographic evaluation of the paranasalsinus in symptomatic and asymptomatic populations. Otolaryngol Head Neck Surg 1991;104(4):480-3.

[36] Harar RP, Chadha NK, Rogers G. The role of septal deviation in adult chronic rhinosinusitis a study of 500 patients. Rhinology 2004;42(3):126-30. 
[37] Soler ZM, Mace JC, Litvack JR, et al. Chronic rhinosinusitis, race and ethnicity. Am J Rhinol Allergy 2012;26(2):100-16.

[38] Smith KA, Smith TL, Mace JC, et al. Endoscopic sinus surgery compared to continued medical therapy for patients with refractory chronic rhinosinusitis. Int Forum Allergy Rhinol 2014;4(10):823-7.

[39] Likness MM, Pallanch JF, Sherris DA, et al. Computed tomography scan as an objective measure of disease severity in chronic rhinosinusitis. Otolaryngol Head Neck Surg 2014;150(2):305-11.

[40] Amodu EJ, Fasunla AJ, Akano AO, et al. Chronic rhinosinusitis: correlation of symptoms with CT scan findings. Pan African Medical Journal 2014;18:40.

[41] Chakrabarti A, Rudramurthy SM, Panda N, et al. Epidemiology of chronic fungal rhinosinusitis in rural India. Mycoses 2015;58(5):294-302. 